\title{
Designing the Macrocyclic Dimension in Main Group Chemistry
}

Hao-Che Niu, ${ }^{[a]}$ Alex J. Plajer, ${ }^{[a]}$ Raul GarciaRodriguez, ${ }^{[b]}$ Sanjay Singh, ${ }^{[c]}$ Dominic S. Wright ${ }^{*[a]}$

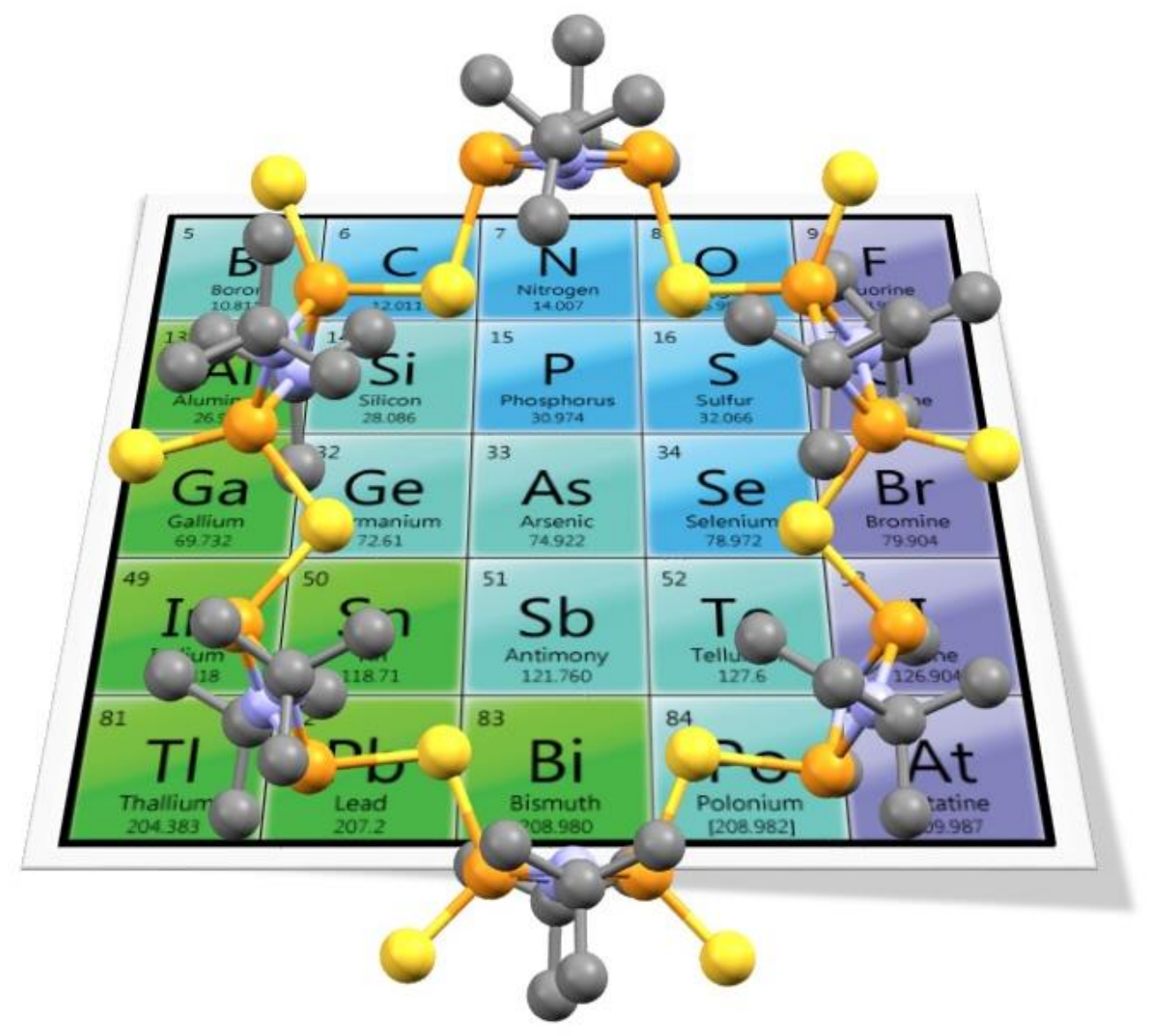

The systematic building of large macromolecular arrangements based on non-carbon elements is a significant challenge. Our aim in the past two decades has been to develop robust synthetic methods to construct new types of main group architectures in a methodical way. This concept article addresses the fundamental thermodynamic and kinetic problems involved in the design of main group macrocycles and looks to future developments of macromolecules in this area. 
Abstract: Outside the confines and well-established domain of organic chemistry, the systematic building of large macromolecular arrangements based on non-carbon elements represents a significant and exciting challenge. Our aim in the past two decades has been to develop robust synthetic methods to construct new types of main group architectures in a methodical way, principles of design that parallel those used in the organic arena. This concept article addresses the fundamental thermodynamic and kinetic problems involved in the design and synthesis of main group macrocycles and looks to future developments of macromolecules in this area, as well as new applications in coordination chemistry.

\section{Introduction}

While organic macrocycles based on thermodynamically stable carbon frameworks, are a central area of modern chemistry (with extensive applications in the fields of coordination chemistry, catalysis and extraction, to name but a few), ${ }^{\left[{ }^{1}\right]}$ functional inorganic macrocycles whose frameworks are constructed solely from inorganic elements are rare. ${ }^{[2]}$ In addition, few general families of inorganic systems have been identified, unlike their organic counterparts which have been derivatized extensively and span a diverse range of structural and donor/acceptor types (including, crown ethers (A), calixarenes (B) and porphyrins (C), Fig. 1).

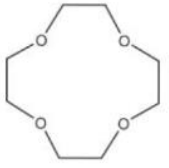

A

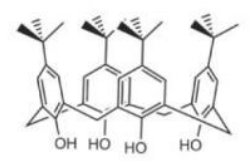

B
Fig. 1 Representative examples of some common organic macrocycles: (A) a crown ether, (B) a calixarene and (C) a porphyrin.

Since most of the elements in the periodic table are metals it is perhaps unsurprising that the vast majority of macrocyclic inorganic systems are metallocycles. In the limited cases in which host-guest chemistry has been explored, their behavior is dominated by anion coordination through the electropositive

[a] Prof. D. S. Wright, Mr. H.-C. Niu, Mr. A. J. Plajer

Chemistry Department, Lensfield Road,

Cambridge University

Cambridge CB2 1EW

E-mail: dsw1000@cam.ac.uk

[b] Dr. R. Garcia-Rodriguez, GIR MIOMeT-IU Cinquima-Química Inorgánica, Facultad de Ciencias, Campus Miguel, Delibes, Universidad de Valladolid 47011 Valladolid, Spain.

[c] Dr. S. Singh, Department of Chemical Sciences, Indian Institute of Science Education and Research Mohali, Knowledge City, Sector 81, SAS Nagar, Mohali 140306, Punjab (India). metal centres of the macrocyclic hosts. ${ }^{[3]}$ This is in contrast to the well-developed host-guest chemistry of organic macrocyles in which anion, cation and neutral guest coordination are commonplace. ${ }^{[4]}$ Examples of anion coordination by inorganic systems are seen in Hawthorne's mercuracarborands (Fig. 2a) ${ }^{[3 a]}$ and Mulvey's inverse crowns (Fig. 2b), ${ }^{[3 b]}$ which can exhibit both anionselective behavior as well as the ability to coordinate highly unusual anions (such the double 2,5-C-H arene deprotonation of toluene witnessed in the example shown in Fig. $\left.2 b^{[5]}\right)$. The main point is that very few donor-type macrocycles have been reported. An early example is the twelve-membered phosph(V)azane $\left[\left(\mathrm{Me}_{2} \mathrm{~N}\right)_{2} \mathrm{PN}\right]_{6}$ which was found to coordinate $\mathrm{Cu}^{2+}$ within its cavity (Fig. 3a). ${ }^{[6]}$ Other more recent examples of cation coordination have been found in the case of cyclic silicones, which are analogous to crown ethers (e.g., the potassium complex shown in Fig.3b). ${ }^{[7]}$ (a)

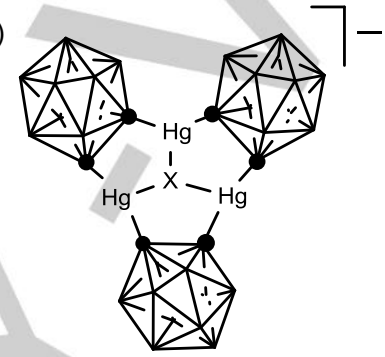

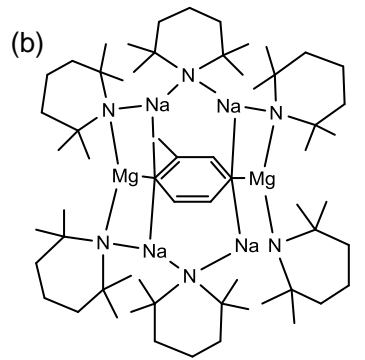

Fig. 2 (a) Host-guest complex of a metallocarborand, in which the 1,2- $\mathrm{B}_{10} \mathrm{C}_{2}$ carborane units link the $\mathrm{Hg}^{\prime \prime}$ centres together in the host which coordinates halide ions (X). (b) An inverse crown complex of a heterometallic $\mathrm{Mg}^{11} / \mathrm{Na}$ imido host coordinating an unusual 2,5-deprotonated toluene dianion. (a)

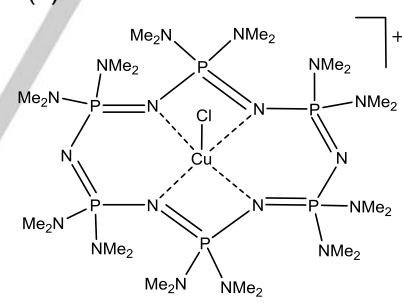

(b)

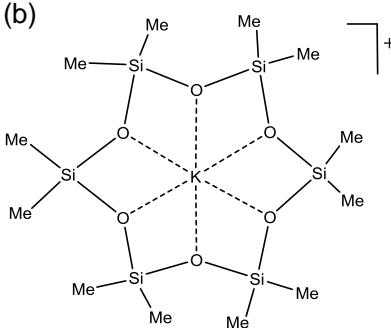

Fig. 3 (a) A phosph(V)azene macrocycle coordinating a Cull ion. (b) A potassium complex of a cyclic silicone macrocycle.

Some of the fundamental issues to consider in the development of any stable inorganic macrocyclic system relate to bond energy and ionicity, since for any host macrocycle to exist in the absence of a guest, it is clear that bonding within its framework should be both stable and directional. A guide to both of these factors is a graph of the heteroatomic bond energy versus the ionic contribution to the bonds, derived from the definition of Pauling electronegativity (Fig. 4, which shows a range of element-element, element- $\mathrm{O}$ and element- $\mathrm{N}$ bonds). ${ }^{[8]}$ The kinetic and thermodynamic stability as well as the rigidity of carbon based macrocycles can be seen to stem in large part from the high stability of the framework bonds (C-C, C-N, C-O) combined with 
the relatively low ionic contribution to the bond character. For elements beyond the second period of the periodic table, however as a particular $p$-block group is descended orbital energy/size mismatching will tend to lead to weaker bonds. Although this is off-set to some extent by an increase in the ionic contribution to the bond energy, this contribution has the detrimental effect of increasing the polarity of the bonds (leading to kinetic instability and non-directionality of bonding, in particular). The 'sweet-spot' in the search for frameworks which are likely to support rigid macrocycles is located around the classical carbon area (as highlighted in Fig. 4). This is largely borne out by a more extensive literature survey of constitutionally-stable main group macromolecular systems, which are far more prevalent in this area, and provides a useful starting point in any planned synthesis of main group macrocycles.

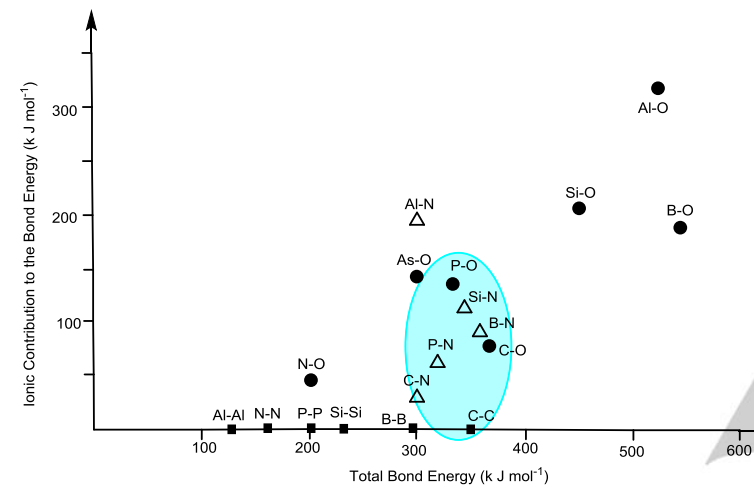

Fig. 4 Background consideration of bond energy and bond polarity, showing the 'sweet spot' located around the classical organic area.

Our interest in this area arose initially through a chance discovery. With the intention of obtaining a heterometallic $\mathrm{Sn}^{\prime \prime} / \mathrm{Sb}^{\prime \prime \prime}$ cage, the lithium salt of the tris(amido)stannate anion [ $\mathrm{Sn}(2-\mathrm{MeO}-$ $\left.\left.\mathrm{C}_{6} \mathrm{H}_{4} \mathrm{NH}\right)_{3}\right]^{-}$was reacted with the potent base $\mathrm{Sb}\left(\mathrm{NMe}_{2}\right)_{3} .{ }^{[9 a]}$ The surprising product of this reaction is the hexameric $\mathrm{Sb}^{\mathrm{III}}$ macrocycle $\left[\left\{\mathrm{Sb}\left(\mu-2-\mathrm{MeO}-\mathrm{C}_{6} \mathrm{H}_{4} \mathrm{~N}\right)\right\}_{2}\left(\left(\mu-2-\mathrm{MeO}-\mathrm{C}_{6} \mathrm{H}_{4} \mathrm{~N}\right)\right]_{6}\right.$ (1) (Fig. 5), having a cyclic arrangement of six $\mathrm{Sb}_{2} \mathrm{~N}_{2}$ ring units bridged by imido- $\mathrm{N}$ atoms. The overall arrangement is toroidal, with the $\mathrm{Sb}_{2} \mathrm{~N}_{2}$ ring units being roughly perpendicular to the $\mathrm{Sb}_{12}$ mean plane. A similar $\mathrm{Sb}^{\mathrm{III}}$ macrocycle was later obtained by Norman and coworkers using a more direct approach. ${ }^{\left[{ }^{[b]}\right.}$ For us, the significance of this result was the potential that $\mathbf{1}$ may represent the first recognizable example of a broader family of macrocyclic compounds of this type within the $p$-block. A significant clue to this was provided by the series of previously reported isoelectronic species $\left[\{\mathrm{P}(\mu-\mathrm{NR})\}_{2}(\mu-\mathrm{NR})\right]_{2}(2), \quad\left[\{\mathrm{Sn}(\mu \text {-PR })\}_{2}(\mu-\mathrm{PR})\right]_{2}^{4-}(\mathbf{3})$ and $\left[\{\operatorname{MeAl}(\mu-\mathrm{PCy})\}_{2}(\mu-\mathrm{PR})\right]_{2}{ }^{4-}(4)(\mathrm{Cy}=\mathrm{cyclohexyl})($ Fig. 6$),{ }^{[10]}$ which in the light of the structure of 1 could be reappraised as 'dimeric' macrocycles with the same architecture.

The big question, however, was how can we develop systematic/general synthetic methods to this type of macrocycle? We have previously surveyed the development of this and related areas of macrocyclic main group chemistry in depth in $2010 .^{[11]}$ In this concept article the focus is on the development of targeted synthesis in this area using newly developed reactions and building blocks.

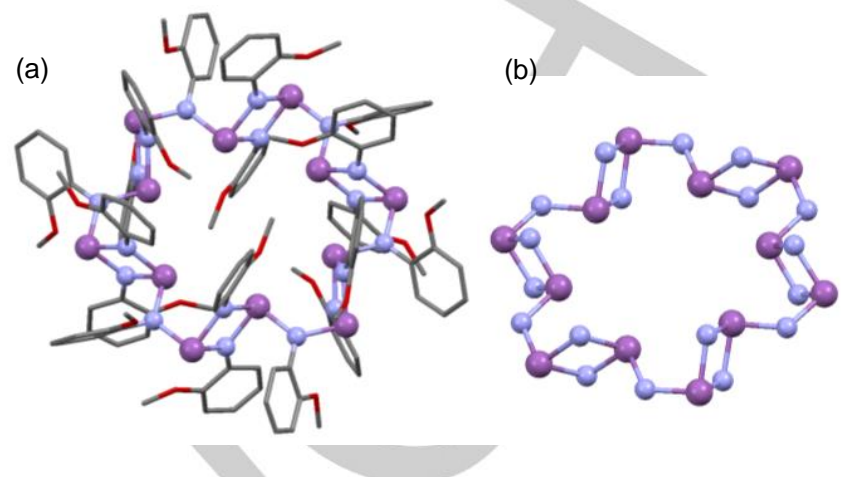

Fig. 5 (a) Structure of the Sb"I macrocycle 1. (b) the core arrangement, showing only the $\mathrm{Sb}$ and $\mathrm{N}$ atoms. Sb (magenta), $\mathrm{N}$ (mauve).

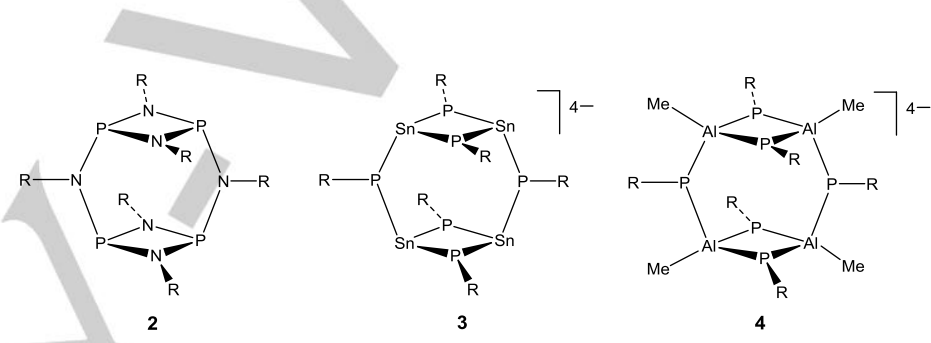

Fig. 6 Isoelectronic 'dimeric' macrocycles.

\section{Establishing the Synthetic Methodology - N-bridged Macrocycles}

A simple nucleophilic approach to macrocycles of this type can be deduced from a retrosynthetic fragmentation of the general macrocyclic framework (Scheme 1).

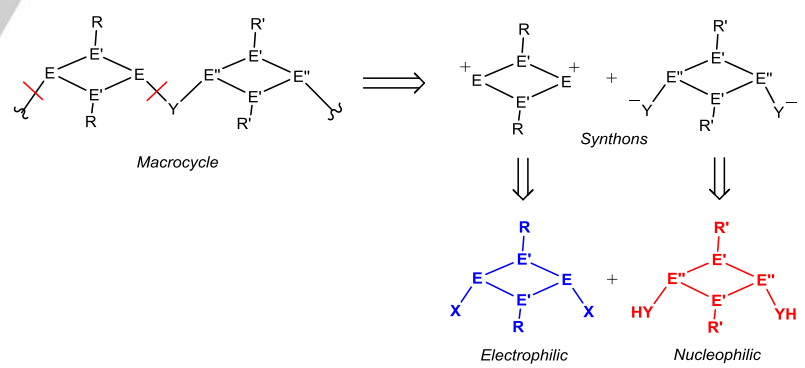

Scheme 1 Retrosynthetic analysis of a general macrocyclic framework of this type, where E, E' and E" are $p$-block elements (or groups), $\mathrm{Y}$ is a linking atom or group and $\mathrm{X}$ is a leaving group.

Higher-order macrocycles related to $\mathbf{2}$ were an attractive target owing to the high bond energy and relatively low polarity of the $P$ $\mathrm{N}$ bonds (as seen diagrammatically in Fig. 4), and these therefore became the focus of future studies by us in this area. It was reasoned that reduction of the steric demands of the $\mathrm{P}_{2} \mathrm{~N}_{2}$ bridging groups of $\mathbf{2}$ might be in itself enough to allow the expansion of the macrocyclic framework. The novel nucleophilic 
synthetic building block $\left[\left(\mathrm{NH}_{2}\right) \mathrm{P}\left(\mu-\mathrm{N}^{t} \mathrm{Bu}\right)\right]_{2}\left(6 \mathrm{H}_{2}\right)$ is obtained in good yield by the simple reaction of the previously reported phosph(III)azane dimer $\left[\mathrm{CIP}\left(\mu-\mathrm{N}^{t} \mathrm{Bu}\right)\right]_{2}$ (5) with a solution of excess ammonia in THF (Scheme 2). ${ }^{[12]}$

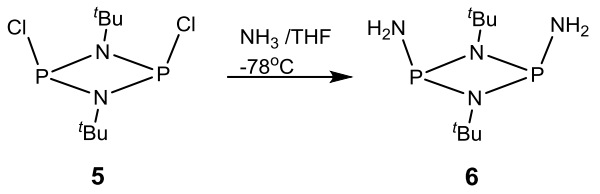

Scheme 2 Formation of the key nucleophilic building block $6 \mathrm{H}_{2}$.

Like 5 and the majority of phosph(III)azane dimers reported, ${ }^{[13]}$ $6 \mathrm{H}_{2}$ exhibits a preference for the cis-isomer in the solution and solid states (Fig. 7). This is one of the key factors favoring the use of cyclodiphosphazanes in macrocycle synthesis, since the cisconformation effectively pre-organises the components for macro-cyclisation during assembly. The nucleophilic precursor $6 \mathrm{H}_{2}$ is readily condensed with the electrophilic component 5 at $78^{\circ} \mathrm{C}$ in the presence of excess $\mathrm{Et}_{3} \mathrm{~N}$ (as a Brønsted base) to give the tetrameric macrocycle $\left[\left\{\mathrm{P}\left(\mu-\mathrm{N}^{t} \mathrm{Bu}\right)\right\}_{2}(\mathrm{NH})\right]_{4}(7)$ in an isolated yield of $67 \%$ (an overall yield of $30 \%$ starting from the readily available $\mathrm{PCl}_{3}$ and ${ }^{t} \mathrm{BuNH}_{2}$ ) (Scheme 3). ${ }^{[12]}$ This reaction is remarkably selective, as shown by the in situ ${ }^{31} \mathrm{P}$ NMR of the reaction mixture at room temperature which shows almost quantitative formation of 7 .
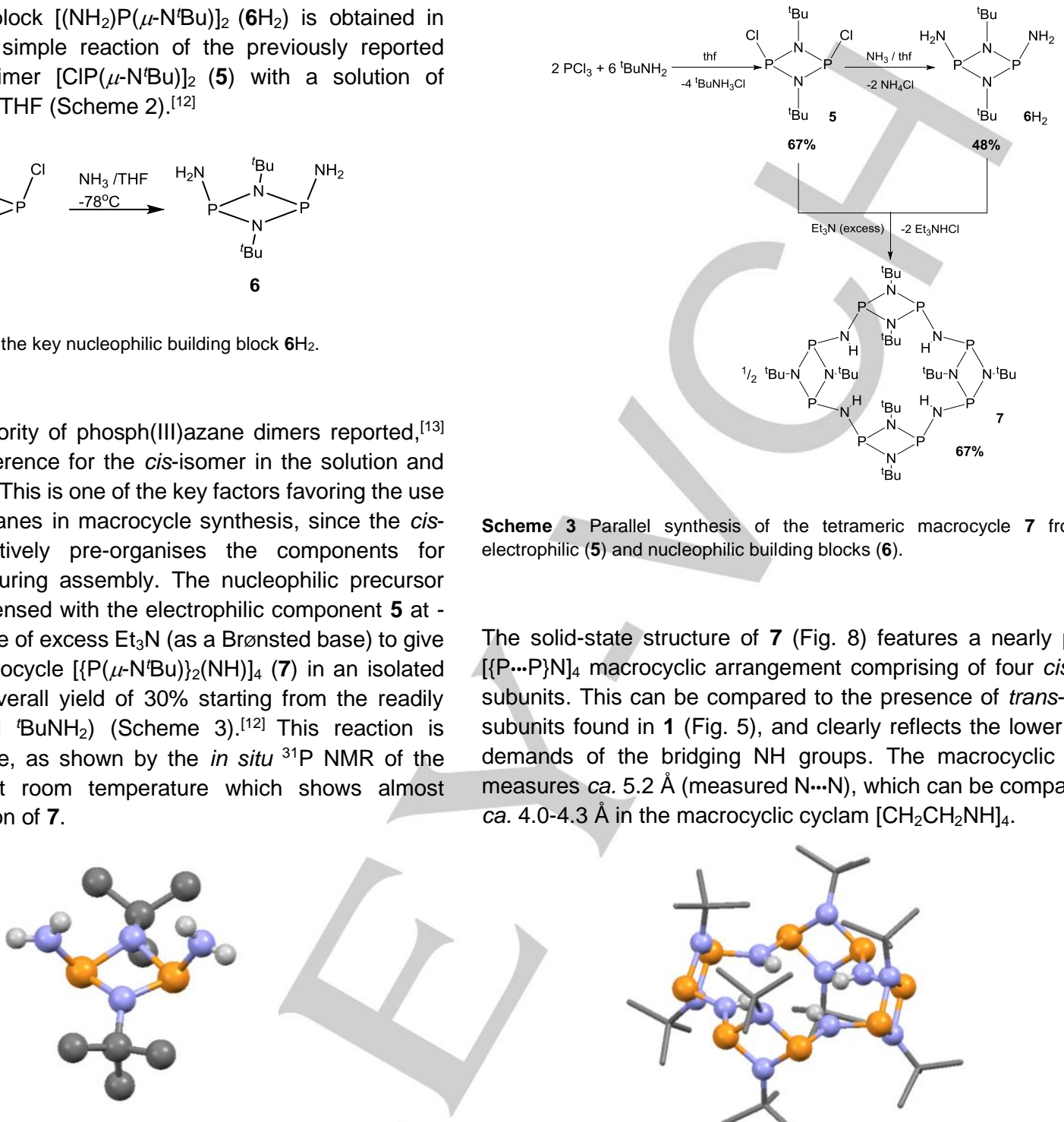

Scheme 3 Parallel synthesis of the tetrameric macrocycle 7 from the electrophilic (5) and nucleophilic building blocks (6).

The solid-state structure of 7 (Fig. 8) features a nearly planar $[\{\mathrm{P} . . . \mathrm{P}\} \mathrm{N}]_{4}$ macrocyclic arrangement comprising of four cis- $\mathrm{P}_{2} \mathrm{~N}_{2}$ subunits. This can be compared to the presence of trans- $-\mathrm{Sb}_{2} \mathrm{~N}_{2}$ subunits found in $\mathbf{1}$ (Fig. 5), and clearly reflects the lower steric demands of the bridging $\mathrm{NH}$ groups. The macrocyclic cavity measures ca. $5.2 \AA$ (measured N...N), which can be compared to ca. 4.0-4.3 $\AA$ in the macrocyclic cyclam $\left[\mathrm{CH}_{2} \mathrm{CH}_{2} \mathrm{NH}\right]_{4}$.

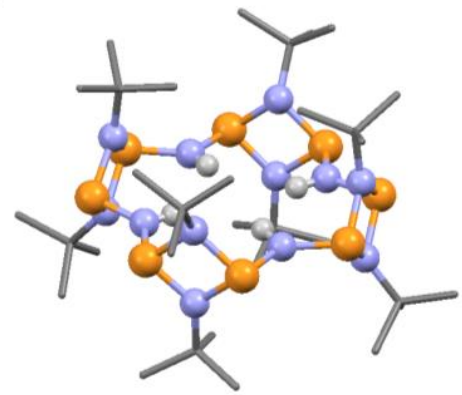

Fig. 7 The cis-arrangement of the $-\mathrm{NH}_{2}$ groups of $6 \mathrm{H}_{2}$ in the solid- state structure. $\mathrm{P}$ (orange), $\mathrm{N}$ (mauve).

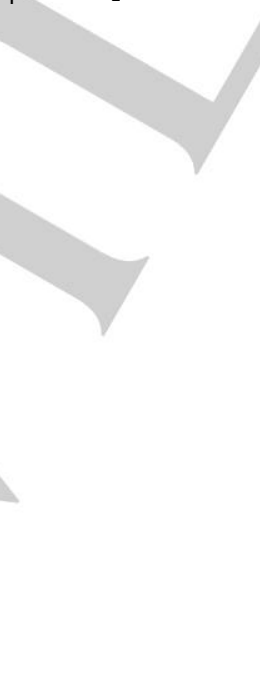

Fig. 8 Structure of the tetramer 7. P (orange), N (mauve).

Although 7 is generated almost quantitatively, further in situ ${ }^{31} \mathrm{P}$ NMR investigation of the reaction at low temperature shows that another minor product is always formed (in variable amounts of about $1-5 \%$ of the total phosphorus signal). This species is the host-guest complex $\left[\left\{\mathrm{P}\left(\mu-\mathrm{N}^{t} \mathrm{Bu}\right)\right\}_{2}(\mathrm{NH})\right]_{5}(\mathrm{HCl})(\mathbf{8} \cdot \mathrm{HCl})$, composed of a pentameric $\left[\{\mathrm{P}(\mu-\mathrm{N} t \mathrm{Bu})\}_{2}(\mathrm{NH})\right]_{5}$ macrocycle which coordinates a $\mathrm{Cl}^{-}$anion at the centre of the planar $\left[\{\mathrm{P} . . . \mathrm{P}\} \mathrm{N}_{5}\right.$ core using the five $\mathrm{N}-\mathrm{H}$ groups (with a $\mathrm{H}$-atom bonded to a P-centre of the macrocycle) (Fig. 9). ${ }^{[14]}$ The macrocyclic cavity of 8 is ca. 6.8 $\AA$ (measured N...N). 


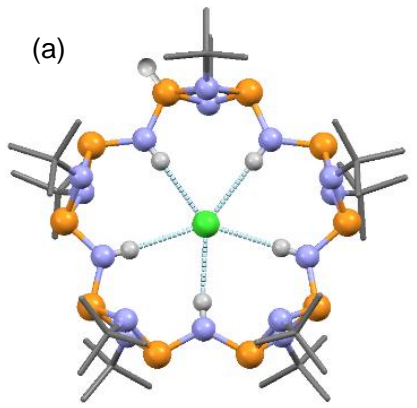

(b)

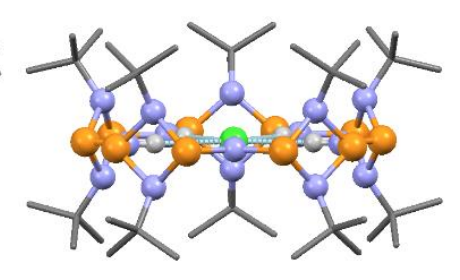

Fig. 9 Structure of the host-guest complex $8 \cdot \mathbf{H C l}$ (top-view (a); side-view (b)). $\mathrm{P}$ (orange), $\mathrm{N}$ (mauve), $\mathrm{Cl}$ (green).

The structure of this minor product illustrates that, in addition to the pre-organisation of the cis-building blocks, templating by $\mathrm{Cl}^{-}$ also directs the formation of a macrocycle rather than polymers. The formation of the pentameric macrocyclic core of $\mathbf{8}$, with an uneven number of $\mathrm{P}_{2} \mathrm{~N}_{2}$ units, clearly cannot occur by the stepwise/alternate condensation of the building blocks 5 and $6 \mathrm{H}_{2}$, for which only macrocycles with an even number of $\mathrm{P}_{2} \mathrm{~N}_{2}$ subunits could be constructed (like 7, Scheme 3). Extensive ${ }^{31} \mathrm{P}$ NMR studies of the reactions of the precursors 5 and $6 \mathrm{H}_{2}$ under a range of conditions reveal the importance of $\mathrm{Cl}^{-}$templating in this reaction and indicate that a common intermediate 9 (Scheme 4) is responsible for the formation of both the tetramer 7 and pentamer 8. While 7 results from ring closure of 9 (with the elimination of $\mathrm{Et}_{3} \mathrm{NHCl}$ ), 8 results from the further insertion of a unit of the nucleophilic component $6 \mathrm{H}_{2}$ (with loss of $\mathrm{NH}_{4} \mathrm{Cl}$ ). ${ }^{[15]}$

Fascinating insight into the mechanism of selection of the tetrameric or pentameric arrangements is revealed by the effects of addition of excess of different halide ions to the reaction. ${ }^{[15]}$ While tetramer $\mathbf{7}$ is formed almost quantitatively in the reaction shown in Scheme 3, remarkably, pentamer $\mathbf{8}$ is produced almost quantitatively if the reaction is performed in the presence of excess Lil (with the order of selection of 8 being $\mathrm{I}^{-}>\mathrm{Br}^{-}>\mathrm{Cl}^{-}$). This is opposite to the thermodynamic stability of the host-guest complexes $[8 \cdot \mathrm{X}]^{-}\left(\mathrm{X}=\mathrm{Cl}^{-}>\mathrm{Br}^{-}>\mathrm{I}^{-}\right)$from DFT calculations, as expected on the basis of weaker $\mathrm{N}-\mathrm{H}$...। $\mathrm{H}$-bonding. The reasons for this switch in selectivity are entirely kinetic in origin (Scheme 5). For the smaller halide ion $\mathrm{Cl}^{-}$the rate of ring closure to the tetramer $\mathbf{7}$ is greater than that for further insertion of $\mathbf{5}$ to give the pentamer $8\left(k_{1}>k_{2}\right)$. This is an example of negative templating, ${ }^{[17]}$ in which selection of $\mathbf{7}$ is due to slowing of the rate of formation of 8. In the case of $\mathrm{I}^{-}$, however, the $-\mathrm{NH}_{3}{ }^{+}$and $-\mathrm{Cl}$ termini of $\mathbf{9}$ are held further apart at optimum separation for the insertion of $\mathbf{5}$ to give the pentamer $\mathbf{8}$. This is an example of positive templating, in which 8 is favoured due to the accelerated rate $\left(k_{2}>k_{1}\right)$.

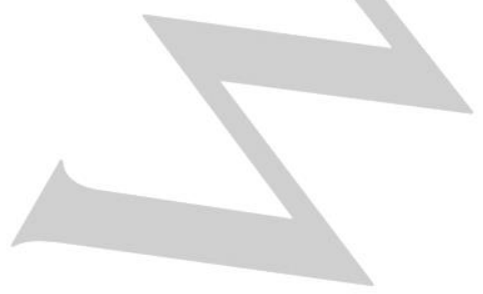

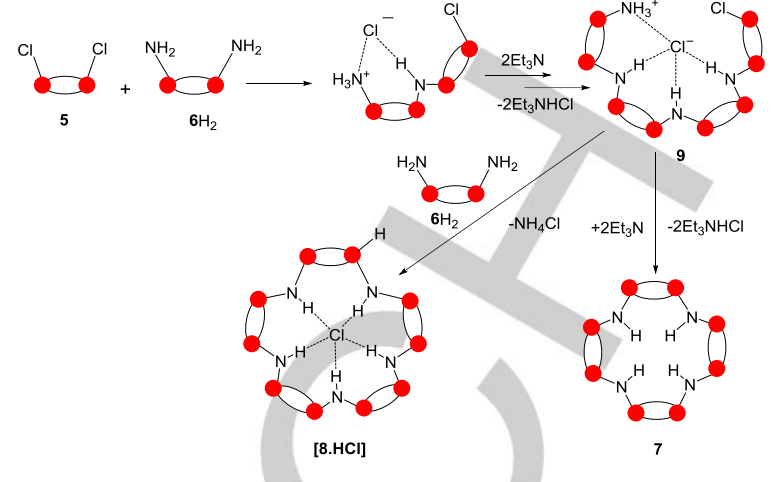

Scheme 4 Mechanism of formation of 7 and 8 through the common intermediate 9.

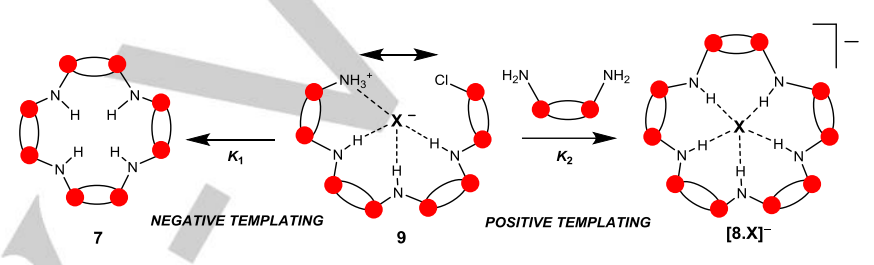

Scheme 5 Positive and negative templating in the selection of the tetramer 7 and pentamer 8 .

Using a ten-fold excess of Lil and adjusting the stoichiometry to the required $3: 2$ ratio (of compounds $6 \mathrm{H}_{2}$ and 5 , respectively) for the formation of $\mathbf{8}$ provides a preparative route to the pentamer, in the form of the host-guest complex $\left[\left\{\mathrm{P}\left(\mu-\mathrm{N}^{t} \mathrm{Bu}\right)\right\}_{2}(\mu-\right.$ $\mathrm{NH})]_{5} \mathrm{I}^{\mathrm{I}}$.Li(thf $)_{4}{ }^{+}\left(\mathbf{8 I} \cdot \mathrm{Li}(\text { thf })_{4}\right)$. Its solid-state structure reveals a highly distorted pentameric macrocyclic arrangement in which the $\mathrm{I}^{-}$anion is located above one side of the macrocyclic mean plane (cf. the planar structure $(\mathbf{8} \cdot \mathrm{HCl})\left(\right.$ Fig. 10)). ${ }^{[15]}$ The free pentamer 8 can be released by the reaction of $8 \mathrm{I} \cdot \mathrm{Li}(\text { thf })_{4}$ with $\mathrm{MeONa}(\rightarrow \mathrm{Nal}$ $+\mathrm{LiOMe}+8) \cdot{ }^{[16]}$

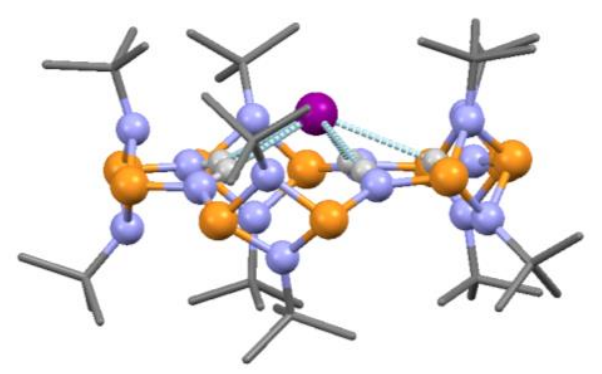

Fig. 10 Structure of the anion $[\mathbf{8} \cdot 1]$, showing the distorted arrangement of the macrocycle. P (orange), N (mauve), I (purple), N-H atoms (light grey).

\section{Isoelectronic Nucleophilic Precursors - Group 16 Bridged Macrocycles}

Now that the synthetic methodolgy had been established with $\mathrm{N}$ $\mathrm{H}$ bridged macrocycles, the next target was to explore the scope 
of this approach to macrocycles containing other heteroatom bridges. The obvious target are macrocycles containing Group 16 atoms. For this to be accomplished, however, it was necessary to develop new nucleophilic precursors which are isoelectronic with $6 \mathrm{H}_{2}$. Scheme 6 shows the relationship between $6 \mathrm{H}_{2}$ and the new isoelectronic $\mathrm{O}$ - and S-precursor, $10 \mathrm{H}_{2}$ and $11 \mathrm{H}_{2}$. Simple consideration of the bond energies involved explains why $6 \mathrm{H}_{2}$ is most stable in its PIII tautomer, whereas $10 \mathrm{H}_{2}$ and $11 \mathrm{H}_{2}$ will be most stable in their $\mathrm{P}^{v}$ tautomers. This is an interesting case of masked functionality in an inorganic setting.
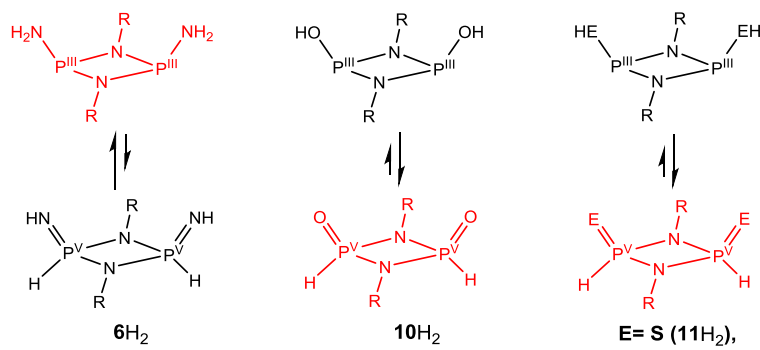

Scheme 6 Isoelectronic nucleophilic building blocks and their preferred tautomers (red).

Precursor $10 \mathrm{H}_{2}$ is readily obtained by the hydrolysis of the $\left[\mathrm{CIP}\left(\mu-\mathrm{N}^{t} \mathrm{Bu}\right)\right]_{2}$ (5) with $\mathrm{H}_{2} \mathrm{O}$ in THF in the presence of excess $\mathrm{Et}_{3} \mathrm{~N}^{\left[{ }^{18]}\right.}$ However, $\mathbf{1 0 H}_{2}$ rapidly dimerises into $[\{\mathrm{O}=(\mathrm{H}) \mathrm{P}(\mu-$ $\left.\left.\left.\left.\mathrm{N}^{t} \mathrm{Bu}\right)\right]_{2}\right\}_{2}(\mu-\mathrm{O})\right]$ (12) above $10^{\circ} \mathrm{C}$ (Scheme 7). Trapping of the framework of $10 \mathrm{H}_{2}$ is achieved by the addition of excess ${ }^{n} \mathrm{BuLi}$, resulting in deprotonation to give the dianion $[10]^{2-}$ which can be reacted in situ to give the O-bridge macrocyclic tetramer $[\operatorname{PP}(\mu-$ $\left.\left.\left.\mathrm{N}^{\mathrm{t} B u}\right)\right\}_{2}(\mu-\mathrm{O})\right]_{4}(\mathbf{1 4})$ (Scheme 7). ${ }^{[18]}$ The solid-state structure of 14 is very similar to the $\mathrm{N}$-bridged analogue 7 (inset to Scheme 7), but with a noticeable contraction in the diameter of the cavity (from $5.2 \AA$ in 7 to $5.05 \AA$ in 14), in-line with the small decrease in bond length of the framework $\mathrm{P}-\mathrm{O}$ bonds compared to $\mathrm{P}-\mathrm{N}$ bonds.

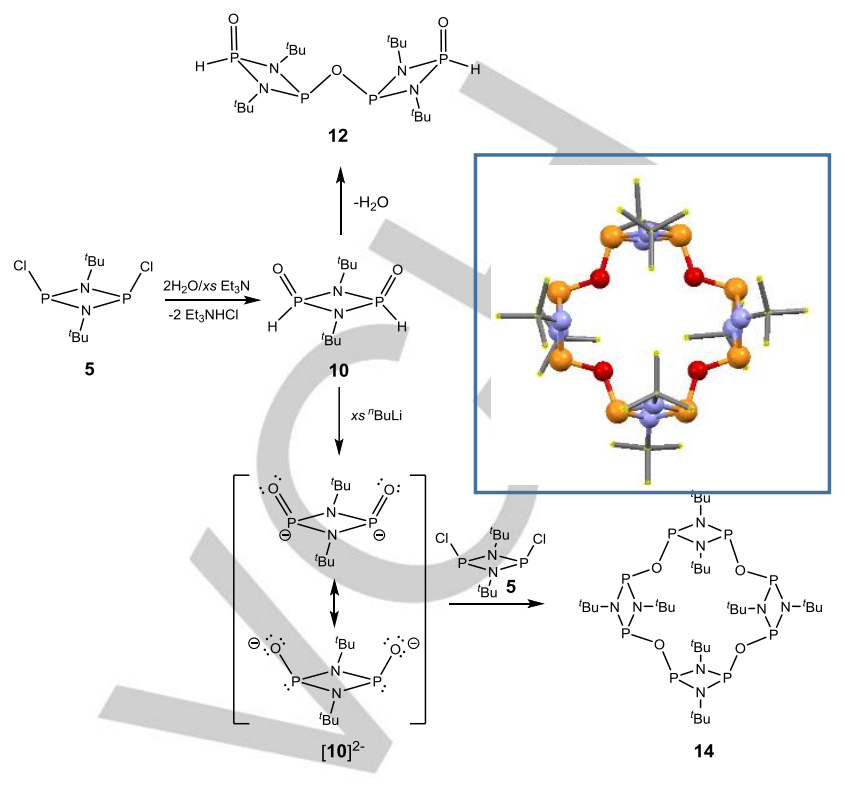

Scheme 7 Formation and trapping of the nucleophilic precursor $10 \mathrm{H}_{2}$ and the formation of the O-bridge tetramer 14 . The inset shows the solid-state structure of 14 [P (orange), mauve $(\mathrm{N}), \mathrm{O}$ (red)]

Direct evidence of the formation of the dianion $[\mathbf{1 0}]^{2-}$ is obtained by the isolation of the intermediate prior to reaction with 5, in the form of the complex 15 (Fig. 11). ${ }^{[19]}$ Complex 15 has three dianion units of $[10]^{2-}$ which surround a central $\mathrm{Li}_{7} \mathrm{Cl}_{7}$ doublecubane unit. The presence of the cis-conformation of the $[10]^{2-}$ dianion and the overall metallocyclic arrangement of 15 suggest that ligand pre-organisation and cation-templating are important in the assembly of macrocycle $\mathbf{1 4}$. However, so far attempts to template the formation of larger O-bridged macrocycles by the addition of other alkali metal ions to the reaction have only led to the formation of $\mathbf{1 4 .}$

A range of nucleophilic precursors $[(\mathrm{S}=)(\mathrm{H}) \mathrm{P}(\mu-\mathrm{NR})]_{2}\left(\mathbf{1 1 H}_{2}\right)$ $\left(\mathrm{R}={ }^{t} \mathrm{Bu}\right.$, Dipp, Mes, $\left.\mathrm{CHPh}_{2}\right)$ can be readily accessed by reactions of the corresponding dichloride dimers $[\mathrm{CIP}(\mu-\mathrm{NR})]_{2}$ with $\mathrm{LiSH}$ at $-78^{\circ} \mathrm{C}$ in THF (Scheme 8). ${ }^{[20 a]}$ The preference for the cis- or transisomer is dependent on the steric bulk of the R-group ('Bu > Dipp $>$ Mes $>\mathrm{CHPh}_{2}$ ), with the cis-isomer being preferred for more sterically demanding groups under normal conditions. The ${ }^{t} \mathrm{Bu}-$ dimer $\left[(\mathrm{S}=)(\mathrm{H}) \mathrm{P}\left(\mu-\mathrm{N}^{t} \mathrm{Bu}\right)\right]_{2}\left(\mathbf{1 1}_{\mathrm{H}^{-}}{ }^{-} \mathrm{Bu}\right)$ (which almost exclusively occurs as the cis-isomer) is deprotonated using a range of organometallic bases. For example, deprotontation with $\mathrm{Bu}_{2} \mathrm{Mg}$ in THF gives $\left[(\mathrm{THF})_{2} \mathrm{Mg}\left\{(\mathrm{S}) \mathrm{P}\left(\mu-\mathrm{N}^{t} \mathrm{Bu}\right)\right\}_{2}\right]\left[\left(\mathbf{1 1}^{\mathrm{t}} \mathrm{Bu}\right) \cdot \mathrm{Mg}(\mathrm{THF})_{2}\right]$ (Fig. $12)$, in which the cis-geometry of the precursor is maintained in the $\left.\left[(\mathrm{S}) \mathrm{P}\left(\mu-\mathrm{N}^{\mathrm{t}} \mathrm{Bu}\right)\right\}_{2}\right]^{2-}$ dianion [11- $\left.{ }^{\mathrm{t}} \mathrm{Bu}\right]^{2-} \cdot{ }^{20 \mathrm{~b}]}$ 


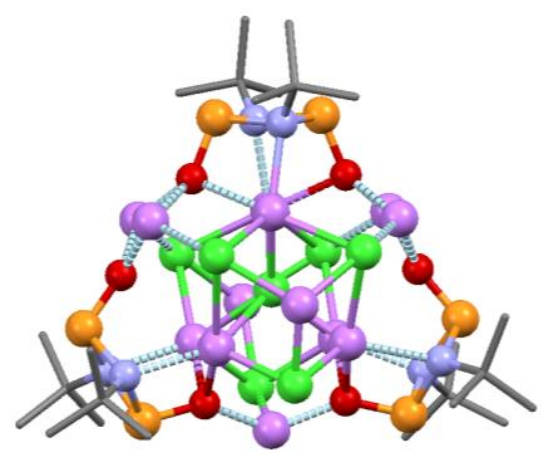

Fig. 11 The core structure of complex 15, in which three dianions $[10]^{2-}$ form a metallocyclic arrangement surrounding a central $\mathrm{Li}_{7} \mathrm{Cl}_{7}$ double-cubane. $\mathrm{Li}$ solvation by THF molecules and disordered atoms have been omitted for clarity. $\mathrm{P}$ (orange), N (mauve), O (red), Li (pink), Cl (green).

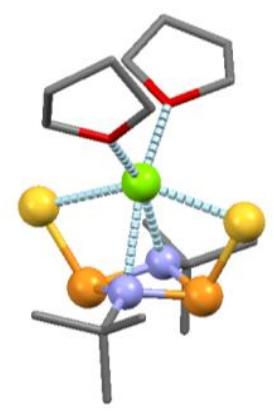

Fig. 12 Structure of the Mg complex of dianion [11-' $\left.{ }^{-} \mathrm{Bu}\right]^{2-}$. P (orange), $\mathrm{N}$ (mauve), $\mathrm{O}$ (red), Mg (green).

Unfortunately, anions like $\left[11^{-} \mathrm{Bu}\right]^{2-}$ are too unstable to be used in the formation of S-bridged, $\mathrm{P}^{\text {III }}$ macrocycles analogous to 14 (Scheme 7). Instead, it is necessary to stabilise the $\mathrm{P}_{2} \mathrm{~N}_{2}$ units of [11- $\left.{ }^{\mathrm{B}} \mathrm{Bu}\right]^{2-}$ prior to cyclisation, by oxidation of the P-centers with elemental $\mathrm{S}$ or $\mathrm{Se}$ (Scheme 8), producing the new $\mathrm{P}^{\vee}$ dianions $\left[(E)(S) P\left(\mu-N^{t} B u\right]_{2}{ }^{2-}[E=S(16 a)\right.$, Se (16b)] (Scheme 8). This approach provides the basis for a modular, one-pot synthesis of a range of $\mathrm{S}$ - and Se-bridged macrocycles. ${ }^{[21]}$ Deprotonation of $11 \mathrm{H}_{2}{ }^{-} \mathrm{B} \mathrm{Bu}$ (most conveniently with $\mathrm{PhCH}_{2} \mathrm{Na}$ ), followed by roomtemperature in situ oxidation with $\mathrm{S}$ or $\mathrm{Se}$, then addition of a range of dichlorides $[\mathrm{CIP}(\mu-\mathrm{NR})]_{2}$ gives the macrocycles $17(\mathrm{E}=\mathrm{S} ; \mathrm{R}=$ ${ }^{t} \mathrm{Bu}$, neopentyl, $R$-1-(2-napthyl)ethyl) or $\mathbf{1 8}\left(\mathrm{E}=\mathrm{Se}\right.$; $\left.\mathrm{R}={ }^{t} \mathrm{Bu}\right)$ in isolated yields of over $80 \%$, having $\left(\mathrm{P}^{\mathrm{III}}\right)_{2}\left(\mathrm{PV}^{\mathrm{V}}\right)_{2}$ backbones (Scheme 8). Significantly, this method allows the synthesis of mixed-ligand macrocycles (containing 'Bu and R' groups), as well as the incorporation of chiral R'-groups (as in the case of $R-1$-(2napthyl)ethyl) for the first time.

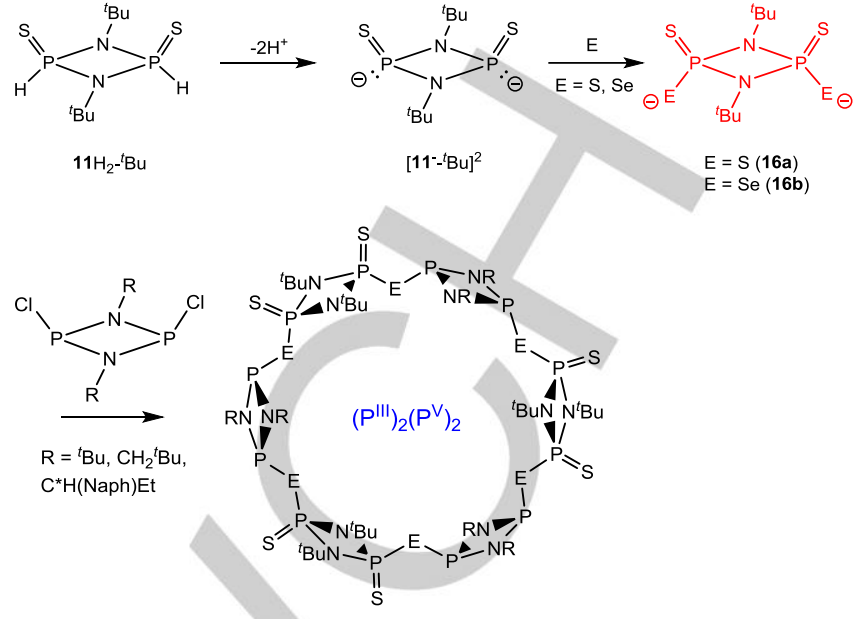

Scheme 8 Deprotonation and oxidation of $11 \mathrm{H}_{2}{ }^{\mathrm{t}} \mathrm{Bu}$ to give anions $16 \mathrm{a}$ and $16 \mathrm{~b}$ followed by macrocyclisation to 17 and 18 [E = S; $R={ }^{t} \mathrm{Bu}\left(17-{ }^{\mathrm{t}} \mathrm{Bu}\right)$, neopentyl (17-neopent), $R$-1-(2-napthyl)ethyl (17- $R$-naphEt). E= Se; $\left.\mathrm{R}={ }^{t} \mathrm{Bu}\left(\mathbf{1 8}^{\mathrm{t}} \mathrm{Bu}\right)\right]$.

The solid-state structure of 17- ${ }^{\mathrm{B}} \mathrm{Bu}$ is shown in Fig. $13 \mathrm{a} .{ }^{[21]}$ The allcis arrangement of the constituent $\mathrm{P}_{2} \mathrm{~N}_{2}$ ring units can be compared to the all-trans arrangement found in the structurallyrelated Sb"I macrocycle 1 (Fig. 5). The diameter of the cavity in 17- ${ }^{\mathrm{B}} \mathrm{Bu}$ is ca. $8.25 \AA$ (measured S...S), significantly smaller than that found in 1 (ca. $13 \AA$ ). Interestingly, although there is a potential choice of bridging atom in the $\mathrm{S} / \mathrm{Se}$ macrocycle $18-{ }^{\mathrm{t}} \mathrm{Bu}$ (Fig. 13b), the Se-atoms bridge the $\mathrm{P}_{2} \mathrm{~N}_{2}$ units exclusively in the solid-state structure. ${ }^{[21]}$ This arrangement not only provides maximum bond energy (preserving $\mathrm{P}=\mathrm{S}$ bonding over $\mathrm{P}=\mathrm{Se}$ bonding), but the presence of longer P-Se bonds in the framework also results in less net steric and electronic repulsion between the ${ }^{t} \mathrm{Bu}$ groups and S-atoms at the periphery of the macrocycle (compared to the S-bridge alternative).
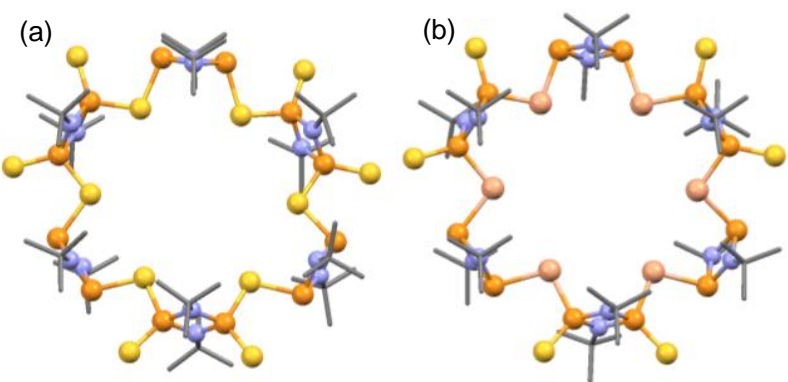

Fig. 13 Structure of the (a) 17-' ${ }^{t} \mathrm{Bu}$ and (b) 18- ${ }^{-} \mathrm{Bu}$. P (orange), N (mauve), S (yellow) Se (faded-pink).

These macrocycles can be derivatised further by $\mathrm{S}$ oxidation of their frameworks. For example, ${ }^{17-t} \mathrm{Bu}$ is converted quantitatively into the all- $P^{\vee}$ macrocycle 19 (Scheme 9). One significant result of oxidation is the large increase in the airstability of the macrocycles. 


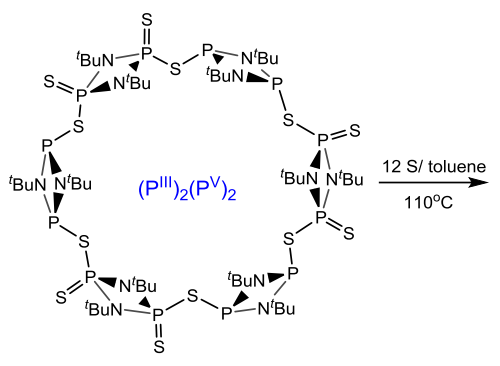

$17-{ }^{t} \mathrm{Bu}$

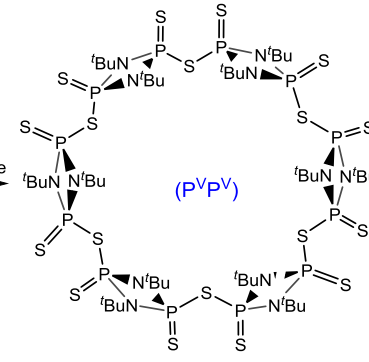

19
Scheme 9 S-oxidation of $17-{ }^{t} \mathrm{Bu}$ into all-P $\mathrm{P}^{\vee}$ macrocycle 19.

In addition to the pathway illustrated in Scheme 8, dianion intermediate $16 \mathrm{~b}$ can be oxidised with $\mathrm{I}_{2}$ to give $-\mathrm{Se}_{2}$ - bridged trimeric macrocycle $\left[\left\{(\mathrm{S}=) \mathrm{P}\left(\mu-\mathrm{N}^{t} \mathrm{Bu}\right)\right\}_{2}(\mu \text {-Se-Se) }]_{3}(20)\right.$ (Fig. 14). ${ }^{[21]}$ This is directly related to the previously reported isoelectronic and isostructural trimers $\left[\left\{\left({ }^{(} \mathrm{BuN}=\right) \mathrm{P}\left(\mu-\mathrm{N}^{\mathrm{t} B u}\right)\right\}_{2}(\mu-\mathrm{E}-\mathrm{E})\right]_{3}(21) \quad(\mathrm{E}=\mathrm{S}$, $\mathrm{Se}){ }^{[22]}$

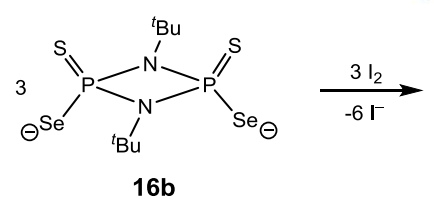

$16 b$

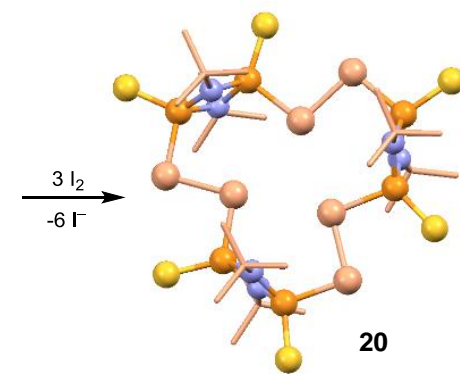

20
Fig. 14 Synthesis and structure of the trimeric macrocycle 20. P (orange), S (yellow), Se (faded-pink).

Macrocycles that are closely related to 17 and 19 can also be constructed selectively via a one-pot Wurtz coupling procedure, involving the reaction of the $\mathrm{P}^{v}$ dichlorides $\left[(\mathrm{E}=)(\mathrm{Cl}) \mathrm{P}\left(\mu-\mathrm{N}^{t} \mathrm{Bu}\right)\right]_{2}(\mathrm{E}$ $\left.=\mathrm{S}(\mathbf{2 2 a}) ;{ }^{[23 \mathrm{a}]} \mathrm{E}=\mathrm{Se}(\mathbf{2 2} \mathbf{b})^{[23 \mathrm{~b}]}\right)$ in toluene. ${ }^{[23]}$ The mechanism of formation of the macrocycles (24) probably involves the 'head-totail' reaction of the transient anionic intermediate 23 , which effectively acts as the nucleophilic and electrophilic component (Scheme 10). The solid-state structure of the S-macrocycle 24a is shown in Fig. 15 and has a distinct, alternating ( $\left.\mathrm{P}^{\prime \prime \prime} \mathrm{PV}\right)$ backbone that can be compared to the $\left(\mathrm{P}^{\mathrm{III}}\right)_{2}\left(\mathrm{P}^{\mathrm{V}}\right)_{2}$ backbone in ${ }^{17}{ }^{-} \mathrm{Bu}$ (Scheme 8, Fig. 13) and the all- $P^{\vee}$ backbone in 19 (Scheme 9). Interestingly, in respect to pre-organisation in these systems, it appears from recent studies of the formation of the S-macrocycle 24a that only the cis-isomer of the precursor 22a may be involved in the formation of the macrocycle, with the trans-isomer (22b) being doubly-reduced to the singlet biradicaloid dianion $\left[(\mathrm{E})(\mathrm{Cl}) \mathrm{P}\left(\mu^{-} \mathrm{B} \mathrm{Bu}\right)\right]_{2}{ }^{2 \cdot \bullet}$ under the reaction conditions. ${ }^{[23 \mathrm{a}]}$

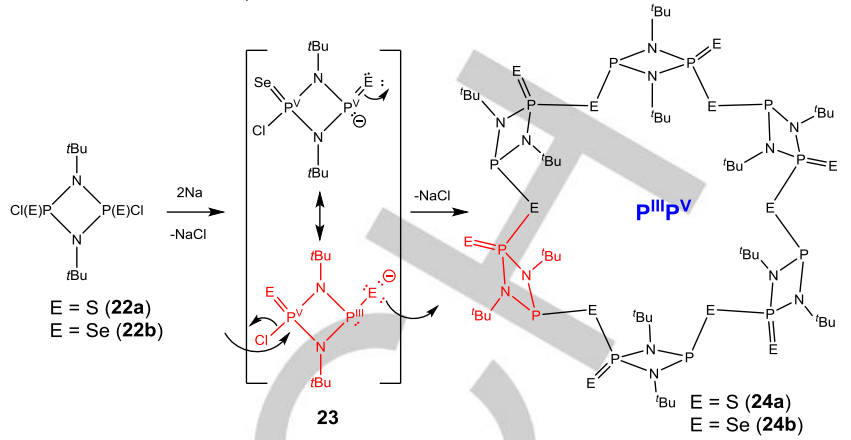

Scheme 10 Mechanism of formation of the S-(22a) and Se-(22b) macrocycles, via Wurtz coupling with $\mathrm{Na}$.

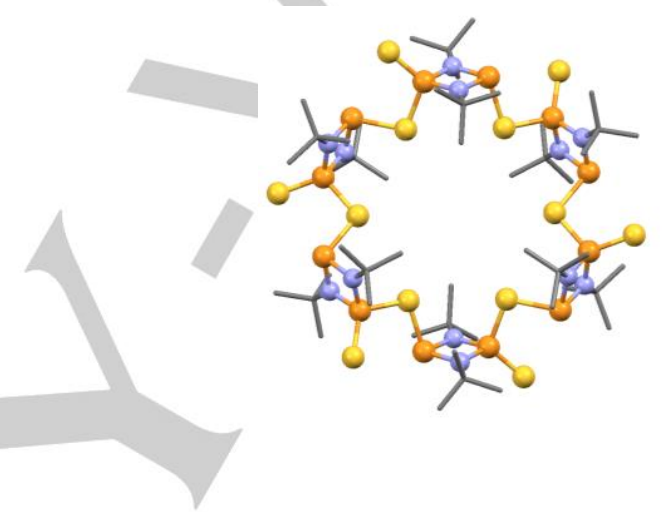

Fig. 15 Structure of 24a. P (orange), N (mauve), S (yellow).

\section{Current and Future Perspectives}

The concept of using dimeric, nucleophililc and electrophilic building blocks has broad applications in the synthesis of a range of new main group macrocycles. These studies have shown that such arrangements can be accessed with surprising selectivity, bearing in mind the simplicity of this strategy, and some interesting parallels relating to selectivity with the synthesis of classical macromolecular organic systems (in particular, the importance of pre-organisation of components and templating). One big advantage of these $\mathrm{P}-\mathrm{N}$ based macrocycles is their general ease of synthesis compared to related organic counterparts, which often require complicated multi-step routes.

Most of these macrocycles are highly soluble in organic solvents and surprisingly air stable, and with effective routes to these species now in hand the next challenge is to explore their coordination chemistry in more detail, particularly with respect to their host-guest behaviour with main group and transition metal cations and organic and inorganic anions. Perhaps the greatest challenge ahead, however, is to develop these systematic synthetic strategies towards even more elaborate macromolecular inorganic systems. 


\section{Acknowledgements}

We gratefully acknowledge the EU (ERC-advanced grant for DSW), and the Spanish MINECO-AEI and the European Union (ESF) for a Ramon y Cajal contract (RG-R, RYC-2015-19035).

Keywords: main group $\cdot p$-block $•$ macrocycles $\bullet$ synthesis $\bullet$ methodology

[1] As evidenced from latest texts on the subject, for example, Macrocycle Synthesis: A Practical Approach, Ed. D. Parker, Oxford University Press, 1996; F. Davis, S. Higson, Macrocycles: Construction, Chemistry and Nanotechnology Applications, Wiley- $\mathrm{VCH}$, Weinheim, 2011; Macrocycles, Topics in Current Chemistry, Springer-Verlag, Berlin Heidelberg, vol, 161, 2013.

[2] Inorganic Rings and Polymers of the p-Block Elements, T. Chivers and I. Manners, RSC Publishing, Chapter 6, 2009; D. S. Wright, Comp. Inorg. Chem.Il, Ed. T. Chivers, vol. 1, 2013, pp. 953.

[3] For example, (a) M. F. Hawthorne, Z. Zheng, Acc. Chem. Res., 1997, 30 267; (b) R. E. Mulvey, Chem. Commun., 2001, 1049; (c) A. J. MartínezMartínez, D. R. Armstrong, B. Conway, B. J. Fleming, J. Klett, A. R. Kennedy, R. E. Mulvey, S. D. Robertson, C. T. O’Hara, Chem. Sci., 2014, 5, 771; (d) T. J. Taylor, C. N. Burress, F. P. Gabbail, Organometallics, 2007, 26, 5252 (e) I. Haiduc, Coord. Chem. Rev., 2017, 338, 1; (f) I. Haiduc, Coord. Chem. Rev., 2017, 348, 71.

[4] (a) Comprehensive Coordination Chemistry II, ed. J. McClevery and T. J. Meyer, Elsevier Pergamon, Oxford, 1995; (b) Comprehensive Supramolecular Chemistry, Ed. J. L. Atwood, J. W. Steed, J. E. D. Davies, D. D. MacNicol, F. Vőgtle, Elsevier Pergamon, Oxford, 1996; (c) Anion Receptor Chemistry, J. L. Sessler, P. A. Gale and W. S. Cho, RSC Publishing, 2006; (d) Encyclopedia of Supramolecular Chemistry, ed. J. L. Atwood and J. W. Steed, RSC Publishing, 2004.

[5] D. R. Armstrong, A. R. Kennedy, R. E. Mulvey, R. B. Rowlings, Angew. Chem. In. Ed., 1999, 38, 131.

[6] (a) W. C. Marsh, N. L. Paddock, C. J. Stewart, J. Trotter, J. Chem. Soc. D, 1970, 1190; (b) W. C. Marsh, J. Trotter, J. Chem. Soc. A, 1971, 1482 (c) J. P. O'Brien, R. W. Allen, H. R. Allcock, Inorg. Chem., 1979, 18, 2230 N. L. Paddock, T. N. Ranganathan, R. D. Sharma, S. J. Rettig, J. Trotter, Can. J. Chem. 1981, 59, 2429; K. D. Gallicano, N. L. Paddock, S. J. Rettig, J. Trotter, Can. J. Chem., 1981, 59, 2435.

[7] (a) J. S. Ritch, T. Chivers, Angew. Chem., Int. Ed., 2007, 46, 4610; (b) M. R. Churchill, C. H. Lake, S.-H. L. Chao, O. T. Beachley, J. Chem. Soc., Chem. Commun., 1993, 1577; C. Eaborn, P. B. Hitchcock, K. Izod, J. D. Smith, Angew. Chem., Int. Ed. Engl., 1996, 34, 2679; (d) A. Decken, J. Passmore, X. Wang, Angew. Chem., Int. Ed., 2006, 45, 2773.

[8] Data taken from Inorganic Chemistry: Principles of Structure and Reactivity, J. Huyee, E. A. Keiter, R. L. Keiter, Harper Collins, $4^{\text {th }}$ Ed., 1993, pp. A-25.

[9] (a) M. A. Beswick, M. K. Davies, M. A. Paver, P. R. Raithby, A. Steiner, D. S. Wright, Angew. Chem., Int. Ed., 1996, 35, 1508; (b) R. Bryant, S. C. James, J. C. Jeffery, N. C. Norman, A. G. Orpen, U. Weckenmann, Dalton Trans., 2000, 4007.

[10] (a) O. J. Scherer, K. Andres, C. Krüger, Y.-H. Tsay, G. Wolmerhäuser, Angew. Chem., Int. Ed., 1980, 19, 571; (b) J. K. Brask, T. Chivers, M. L. Krahn, M. Parvez, Inorg. Chem., 1999, 38, 290; (c) R. E. Allan, M. A. Beswick, N. L. Chromhout, M. A. Paver, P. R. Raithy, A. Steiner, M. Trevithick, D. S. Wright, Chem. Commun., 1996, 1501; (d) F. García, J. P. Hehn, R. A. Kowenicki, M. McPartlin, C. M. Pask, A. Rothenberger, M. L. Stead, D. S. Wright, Organometallics, 2006, 25, 3275; (e) R. E. Allan, M. A. Beswick, P. R. Raithby, A. Steiner, D. S. Wright, Dalton Trans., 1996, 4153.

[11] S. G. González-Calera, D. S. Wright, Dalton Trans. 2010, 39, 5055.
[12] A. Bashall, E. L. Doyle, C. Tubb, S. J. Kidd, M. McPartlin, A. D. Woods, D. S. Wright, Chem. Commun., 2001, 2542

[13] L. Stahl, Coord. Chem. Rev., 2000, 210, 203 and references therein.

[14] A. Bashall, A. D. Bond, E. L. Doyle, F. García, S. J. Kidd, G. T. Lawson, M. C. Parry, M. McPartlin, A. D. Wood, D. S. Wright, Chem. Eur. J., 2002, 8, 3377.

[15] F. García, J. M. Goodman, R. A. Kowenicki, I. Kuzu, M. McPartlin, M. A. Silva, L. Riera, A. D. Woods, D. S. Wright, Chem. Eur. J., 2004, 10, 6066

[16] F. García, R. A. Kowenicki, I. Kuzu, M. McPartlin, L. Riera, D. S. Wright, Inorg. Chem. Commun., 2005, 8, 1060.

[17] S. Anderson, H. L. Anderson and J. K. M. Sanders, Acc. Chem. Res., 1993, 26, 469; S. Anderson, H. L. Anderson and J. K. M. Sanders, J. Chem. Soc., Perkin Trans. 1, 1995, 2255.

[18] S. Gonzalez Calera, D. J. Eisler, J. M. Goodman, M. McPartlin, S. Singh, D. S. Wright, Dalton Trans., 2009, 1293.

[19] W. T. K. Chan, F. García, S. Gonzalez-Calera, M. McPartlin, J. V. Morey, R. E. Mulvey, S. Singh, D. S. Wright, Chem. Commun., 2008, 2251.

[20] (a) C. G. M. Benson, V. Vasilenko, S. G. Calera, L. H. Gade, D. S. Wright, Dalton Trans., 2015, 44, 14242; (b) C. G. H. Benson, A. Plajer A. D. Bond, S. Singh, L. H. Gade, D. S. Wright, Chem. Commun., 2016, 52, 9683.

[21] A. J. Plajer, R. García-Rodríguez, C. G. M. Benson, P. D. Matthews, A. D. Bond, S. Singh, L. H. Gade, D. S. Wright, Angew. Chem., Int. Ed., 2017, 56, 9087.

[22] A. Nordheider, T. Chivers, R. Thirumoorthi, I. Vargas-Baca, J. D. Woollins, Chem. Commun. 2012, 48, 6346.

[23] (a) D. Bawari, B. Prashanth, S. Singh, D. S. Wright, Chem. Eur. J., 2016, 22, 11877; (b) S. González-Calera, D. J. Eisler, J. V. Morey, M. McPartlin, S. Singh, D. S. Wright, Angew. Chem., 2008, 47, 1111. 
WILEY-VCH 


\section{Entry for the Table of Contents}

\section{CONCEPT}

'Circling the Square': Developing systematic strategies to inorganic macrocycles, which parallel the type of design principles used for organic counterparts, is a major challenge. A simple approach involving combination of dimeric (electrophilic and nucleophilic) $\mathrm{P}_{2} \mathrm{~N}_{2}$ ring components has proved to be remarkably selective in building macrocyclic phosphazanes, uncovering the potential for new hostguest chemistry in this area.

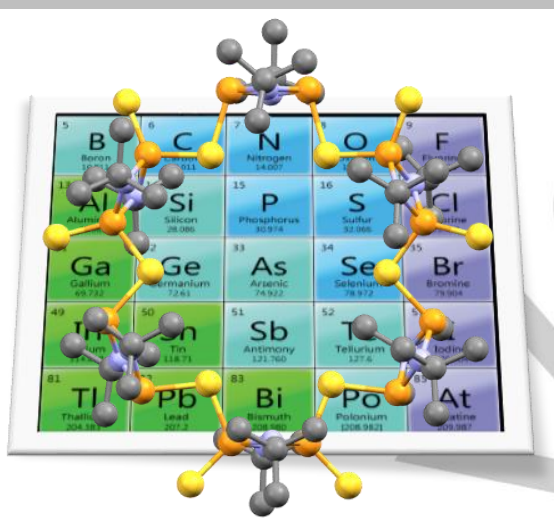

Hao-Che Niu,Alex J. Plajer, Raul GarciaRodriguez, Sanjay Singh,Dominic S. Wright ${ }^{*}$

Page No. - Page No.

Designing the Macrocyclic Dimension in Main Group Chemistry 